\title{
Immunolabelling of SR protein and serotype polysaccharide in Streptococcus mutans
}

\author{
Frederic J. G. Cuisinier, ${ }^{*}$ Jean-Paul Klein and Robert M. Frank \\ Groupe de Recherches U 157, Institut National de la Santé et de la Recherche Médicale, Faculté de Chirurgie Dentaire, \\ 1 place de l'Hôpital, 67000 Strasbourg, France
}

(Received 27 November 1989; revised 8 January 1990; accepted 10 January 1990)

\begin{abstract}
Immunoelectron microscopy was used to determine the accessibility of gold-labelled monoclonal antibodies, specific for the SR protein and serotype polysaccharide, to the surface of viable cells of Streptococcus mutans. The results indicate that both antigens are simultaneously accessible to their respective antibodies.
\end{abstract}

\section{Introduction}

The cell-surface components of Streptococcus mutans appear to play an important role both in saliva-mediated bacterial adherence to the tooth surface and in bacterial agglutination (Loesche, 1986). Therefore several efforts to prevent adherence of $S$. mutans have focused on the production of an effective vaccine comprising isolated purified streptococcal surface components (Russell \& Mestecky, 1986). Current evidence suggests that serotype polysaccharide (Gibbons \& Qureshi, 1979) and antigen I/II, a $140 \mathrm{kDa}$ cell-surface glycoprotein (Russell \& Lehner, 1978), also named B (Russell, 1979), P1 (Forester et al., 1983), IF (Hughes et al., 1980) and Pac (Okahashi et al., 1989) are: (i) implicated in the initial interactions of $S$. mutans and salivary glycoproteins (Russell, 1979), (ii) surface exposed and (iii) accessible to antibodies (Douglas \& Russell, 1984; Schöller et al., 1988). We have shown that when SR protein (a cellsurface component related immunologically to antigen $\mathrm{I} / \mathrm{II})$ is covalently linked to purified serotype $f$ polysaccharide (Wachsmann et al., 1985) and orally administered in liposomes, a local anti-protein and antipolysaccharide immune response is produced (Schöller $e t$ al., 1988). The wide distribution of SR proteins in mutans streptococci (Bruyere et al., 1988) and partial cross-reactivity between serotype $f$ polysaccharide and other serotype polysaccharides (Schöller et al., 1988) makes these antigens of potential use as a vaccine. However, there was no information available as to the accessibility to antibodies of these antigens when they are in their native form on viable streptococci.

Abbreviation: mAb, monoclonal antibody
To investigate whether native SR protein and serotype polysaccharide are accessible to antibodies, we used monoclonal antibodies (mAbs) directed to each component, linked to gold particles. The simultaneous binding of these mAbs to their respective epitopes was visualized by immunoelectron microscopy with each $\mathrm{mAb}$ labelled with gold particles of a different size.

\section{Methods}

Bacterial strain and culture conditions. S. mutans OMZ 175 (serotype $f)$ was grown overnight in Brain Heart Infusion broth. Bacterial cells were collected by centrifugation, washed three times with phosphatebuffered saline (PBS; 0.15 M- NaCl, 0.01 M- $\mathrm{Na}_{2} \mathrm{HPO}_{4} / \mathrm{NaH}_{2} \mathrm{PO}_{4}, \mathrm{pH}$ 7.2) and finally resuspended in PBS.

Monoclonal antibodies. The mAbs used in this study have been previously described and characterized (Schöller et al., 1988; Bruyere et al., 1988). LOSM 11 was obtained after immunization of rats with purified $74 \mathrm{kDa}$ SR protein and fusion of spleen cells with line IR $983 \mathrm{~F}$ (Bruyere et al., 1988). K28 (anti-serotype-f-polysaccharide) was produced in rats immunized with formalin-killed S. mutans OMZ 175 cells according to the standard procedure (Schöller et al., 1988). Both antibodies were of subclass IgG $2 \mathrm{a}$ with $\kappa$ light chains. These antibodies bind to their respective purified antigen, to intact $S$. mutans OMZ 175 cells and interfere with the binding of salivary glycoproteins to $S$. mutans (Schöller et al., 1988; Bruyere et al., 1988).

Immunoelectron microscopy. Protein G (Sigma) was conjugated to either $15 \mathrm{~nm}$ or $5 \mathrm{~nm}$ colloidal gold particles (Janssen) as described by Bendayan (1987); affinity purified mAbs-protein G-gold complexes were prepared according to the method described by Robinson et al., (1984) for mAbs-protein A-gold complexes. Negative controls were provided by non-relevant rat IgG mAbs.

The coated sides of Formvar-covered carbon-stabilized nickel grids were floated for $1 \mathrm{~min}$ at $25^{\circ} \mathrm{C}$ on the streptococcal suspension. The grids were then transferred to drops of reagents in the following sequence: (i) $0.5 \%$ gelatin in PBS $\left(15 \mathrm{~min}, 25^{\circ} \mathrm{C}\right)$; (ii) gold-protein GmAbs complexes $\left(30 \mathrm{~min}, 37^{\circ} \mathrm{C}\right.$ ); (iii) five successive drops of PBS; and (iv) $1 \%$ methylamine tungstate. For double-labelling experiments, 

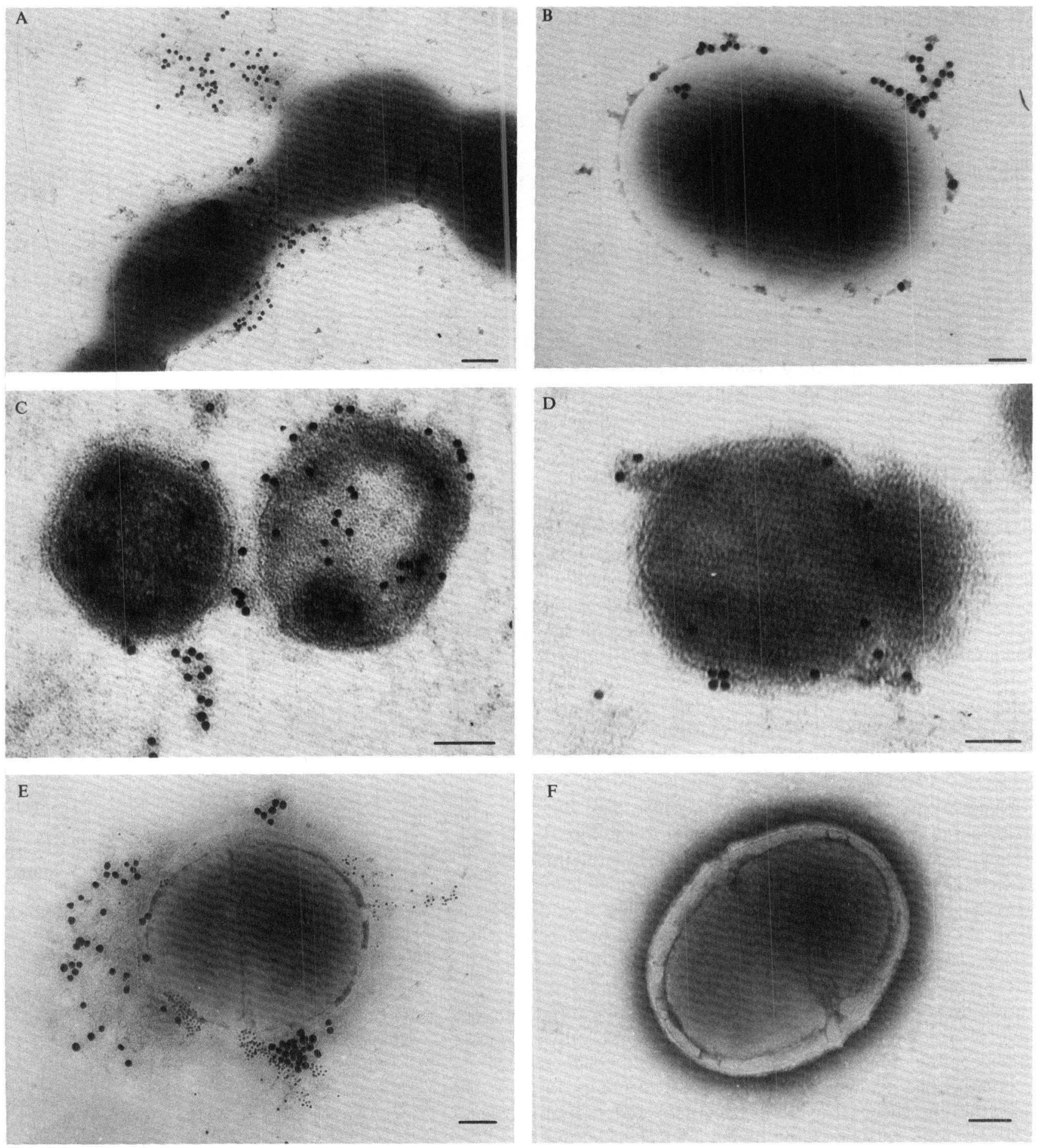

Fig. 1. Binding of mAbs LOSM 11 and K28 to $S$. mutans OMZ 175. A, B, electron micrographs of whole cells of $S$. mutans incubated with LOSM 11 (A) and K28 (B). Note the presence of gold particles complexed to LOSM 11 (anti-protein SR) attached to extruded material in (A). C, D, thin sections of cells incubated with LOSM 11 (C) and K28 (D). E, whole cells of $S$. mutans exposed simultaneously to both mAbs. LOSM 11 was complexed to large $(15 \mathrm{~nm})$ gold particles and $\mathrm{K} 28$ to smaller $(5 \mathrm{~nm})$ particles. F, control incubation of cells with a non-relevant rat $\mathrm{mAb}$. Bars, $0 \cdot 1 \mu \mathrm{m}$. 
the grids were incubated after step (ii) for a second $30 \mathrm{~min}$ period with complexes containing smaller gold particles. The grids were air-dried and examined in a transmission electron microscope (Jeol 100b) at 80 $\mathrm{kV}$.

To prepare thin sections, bacterial suspensions were centrifuged and the pellet was fixed in $2 \%(\mathrm{v} / \mathrm{v})$ glutaraldehyde and $2 \%(\mathrm{v} / \mathrm{v})$ paraformaldehyde in $0.1 \mathrm{M}$-sodium cacodylate buffer ( $\mathrm{pH} 7 \cdot 2$ ), postfixed with $1 \%$ osmium tetroxide in the same buffer and embedded in Epon 812 . Sections were floated on grids, incubated with $10 \%(\mathrm{v} / \mathrm{v})$ aqueous sodium metaperiodate (Bendayan, 1984), rinsed in three changes of distilled water and incubated with the reagents described above. The sections were stained with uranyl acetate and lead citrate, and examined in a Jeol $100 \mathrm{~b}$ transmission electron microscope as above.

\section{Results and Discussion}

mAb LOSM 11 bound readily to cells of $S$. mutans OMZ 175. Gold-labelled antibody was localized at the outer surface of intact cells and also bound to extruded cellwall material, probably representing excreted SR protein (Fig. 1A). These results confirmed previous observation concerning the loose association of antigen-I/II-related proteins with the $S$. mutans cell wall (Russell et al., 1980). Incubation of viable streptococci with the anti-polysaccharide- $f \mathrm{mAb} \mathrm{K} 28$ resulted in a specific cell-wall labelling pattern, and a moderate amount of labelling of the extruded material (Fig. 1B). This localization of the SR and polysaccharide antigens was also confirmed on thin-sections of $S$. mutans cells incubated with either LOSM 11 (Fig. 1C) or with K28 (Fig. 1D). The absence from cross-sections of intracellular labelling of the polysaccharide antigen suggests that the polysaccharide is synthesized at the cell surface, rather than being synthesized in the cytoplasm and then exported into the cell wall. When cells were incubated with non-immune IgG no antibody binding was seen on either cell membrane or extruded cell-wall material (Fig. 1F). To determine the accessibility of both SR protein and serotype polysaccharide, viable $S$. mutans cells were exposed in sequence to antibody LOSM 11 complexed with large gold particles and to antibody $\mathrm{K} 28$ complexed with small gold particles (Fig. 1E). Each antibody exhibited binding to its corresponding epitope on the cell surface and the double labelling was not affected by the order of the incubation sequence. This showed that the antibodies do not interfere with each other in binding to viable streptococci. The simultaneous binding of both kinds of antibody to bacterial cells implies direct availability of the corresponding epitopes at the cell surface. Furthermore, the double accessibility of the antigens suggests the absence of steric hindrance for the fixation of the antibodies and the unmasking of the epitope, probably due to their different localization within the cell-wall region.
In conclusion, our results demonstrate the direct accessibility of both antigens on the $S$. mutans cellsurface to antibodies elicited during immunization experiments with a protein-polysaccharide conjugate, and thus confirm the potential role of such a conjugate as an alternative vaccine against dental caries.

\section{References}

Bendayan, M. (1984). Protein A-gold electron microscopic immunocytochemistry: methods, applications, and limitations. Journal of Electron Microscopy Technique 1, 243-270.

BENDAYAN, M. (1987). Introduction of the protein G-gold complex for high-resolution immunocytochemistry. Journal of Electron Microscopy Technique 6, 7-13.

Bruyere, T., Ackermans, F., Klein, J. P., Pillat, M. \& Frank, R. M. (1988). Monoclonal antibodies against Streptococcus mutans 74 $\mathrm{kDa}$ cell wall saliva receptor $(74 \mathrm{kDa} S R)$ : correlation between antigenic structure and saliva binding sites. FEMS Microbiology Letters 50, 211-215.

Douglas, C. W. I. \& Russell, R. R. B. (1984). Effect of specific antisera upon Streptococcus mutans adherence to saliva-coated hydroxylapatite. FEMS Microbiology Letters 25, 211-214.

FORESTER, H., HUNTER, N. \& KNOX, K. W. (1983). Characteristics of a high molecular weight extracellular protein of Streptococcus mutans. Journal of General Microbiology 129, 2779-2788.

GibBONS, R. J. \& QURESHI, J. V. (1979). Inhibition of adsorption of Streptococcus mutans strains to saliva-treated hydroxyapatite by galactose and certain amines. Infection and Immunity 26, 1214-1217.

Hughes, M., Machardy, S. M., Sheppard, A. J. \& Woods, N. C. (1980). Evidence for an immunological relationship between Streptococcus mutans and human cardiac tissue. Infection and Immunity 27, 576-588.

LOESHE, W. J. (1986). Role of Streptococcus mutans in human dental decay. Microbiological Reviews 50, 353-380.

Oxahashi, N., Sasakawa, C., Yoshikawa, M., Hamada, S. \& Koga, T. (1989). Cloning of a surface protein gene from serotype $c$ Streptococcus mutans. Molecular Biology 3, 221-228.

Robinson, E. N., McGee, Z. A., Kaplan, J., Hammond, M. E., Larson, J. K., Buchanan, T. M. \& Schoolnik, G. K. (1984). Ultrastructural localization of specific gonococcal macromolecules with antibody-gold sphere immunological probes. Infection and Immunity 46, 361-366.

RUSSELL, R. R. B. (1979). Wall-associated protein antigens of Streptococcus mutans. Journal of General Microbiology 114, 109-115.

Russell, M. W. \& LEHNER, T. (1978). Characterisation of antigens extracted from cells and culture fluids of Streptococcus mutans serotype $c$. Archives of Oral Biology 23, 7-15.

Russell, M. W. \& MesteCKy, J. (1986). Potential for immunological intervention against dental caries. Journal de Biologie Buccale 14, 159-175.

Russell, M. W., Bergmeier, L. A., Zanders, E. D. \& Lehner, T. (1980). Protein antigens of Streptococcus mutans: purification and properties of a double antigen and its protease-resistant component. Infection and Immunity 28, 486-493.

Schöller, M., Fargeas, C., Pini, A. \& Klein, J. P. (1988). Monoclonal antibodies to Streptococcus mutans serotype $f$ polysaccharide cross-react with the "mutans group" of oral streptococci. FEMS Microbiology Letters 51, 125-128.

Wachsmann, D., Klein, J. P., Schöller, M. \& FranK, R. M. (1985). Local and systemic immune response to orally administered liposome associated soluble Streptococcus mutans cell wall antigens. Immunology 54, 189-194. 